\title{
Atracció de talent i polarització socioeconòmica a Barcelona
}

\author{
Antonio López-Gay, Centre d'Estudis Demogràfics
}

L’Ajuntament de Barcelona ha facilitat als investigadors per primera vegada l'explotació del registre d'altes per migració i de canvis de domicili incloent el nivell d’instrucció de la població. Amb aquesta dada, a més de la ja coneguda estructura per edat, sexe i origen dels migrants, podem conèixer el perfil educatiu de les persones que arriben a la ciutat i de les que es mouen dintre d'ella. Aquest és un aspecte clau per entendre els processos de polarització i segregació social de la ciutat de Barcelona i dels seus barris.

Les dades mostren que Barcelona té poder. Molt poder per atraure població jove altament qualificada, però poc per distribuir-la de forma homogènia entre els seus barris. Per una banda, la Barcelona més cèntrica exerceix una major atracció a la població més qualificada que arriba a la ciutat, uns barris als quals amb prou feines arriba població menys instruïda. Per l'altra banda, la mobilitat residencial interna dels barcelonins tendeix a perpetuar les diferències socioeconòmiques ja existents en el territori. Els barris de renda familiar més alta retenen i atrauen als més educats, mentre que els de menys renda retenen i atrauen als menys formats, que presenten baixes probabilitats d'ascendir en l'escala residencial. La combinació d'ambdues dinàmiques, doncs, està alimentant el procés de polarització socioeconòmica de la ciutat de Barcelona.

\section{BARCELONATÉ PODER...}

Barcelona té poder d'atracció de població amb alts nivells d'instrucció. Aquest tret ha definit durant dècades el filtre demogràfic barceloní (Cabré i Pujadas, 1982; López-Gay, 2008), però s'ha accentuat en els darrers anys després del descens de la immigració internacional de perfil socioeconòmic baix i l'augment de la més instruïda.

Una mitjana d'unes 80.00o persones han arribat anualment al municipi de Barcelona durant el període 2011-2014, una xifra que equival aproximadament al 5\% de la població de la ciutat. El $45 \%$ d'aquesta població procedia de la resta de Catalunya, el 35\% de l'estranger i el 20\% d'altres punts d'Espanya. Es tracta d'una població eminentment adulta-jove. La meitat té entre 25 i 39 anys i un nivell de formació elevat, sobretot en el cas de les dones (Figura 1A). El 43\% dels homes i el $55 \%$ de les dones d'aquest grup d'edat té estudis universitaris, una proporció que ha anat en
FIGURA 1. Característiques sociodemogràfiques del flux immigratori, 2011-14
A) Fluxos anuals absoluts (mitjana, 2011-14)

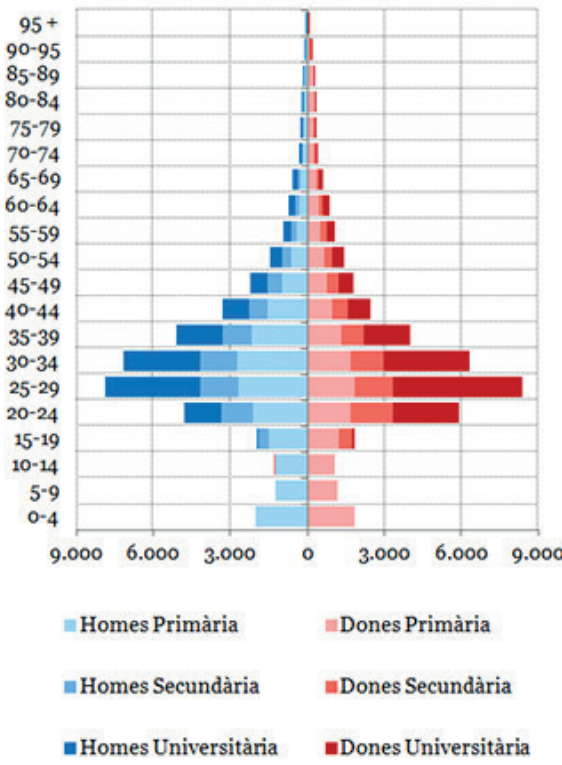

B) Proporció de població amb estudis universitaris, 2011-14

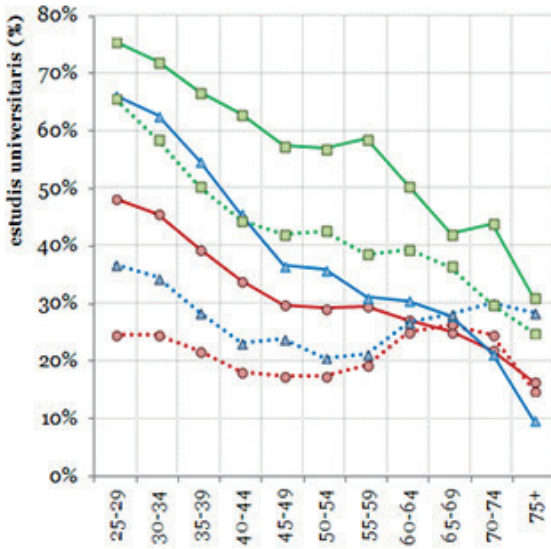

$\multimap-$ Resta Cat. Nac. Esp. (Flux anual $=21.576$ )

..॰.. Resta Cat. Nac. Estr. (Flux anual $=14.931$ )

$\longrightarrow$ Resta Esp. Nac. Esp. (Flux anual = 10.604)

$\cdots \Delta \cdot$ Resta Esp. Nac. Estr. (Flux anual $=5.470$ )

$\rightarrow-$ Resta món Nac. Esp. (Flux anual $=2.705$ )

.. .. Resta món Nac. Estr. (Flux anual = 26.579) 
augment durant el període estudiat (al 2014 va assolir el 47\% entre els homes i el 58\% entre les dones).

Aquestes dades amaguen una heterogeneïtat de perfils en funció de la procedència i nacionalitat (Figura 1B). La població de nacionalitat estrangera procedent de la resta de Catalunya i Espanya és la que presenta un nivell de formació més baix, amb un 30\% d'adultsjoves amb estudis universitaris. En canvi, més del 65\% de la població adulta-jove que procedeix d'altres punts del món, ja sigui de nacionalitat espanyola o estrangera, i la de nacionalitat espanyola que arriba des de la resta d'Espanya té estudis universitaris. Aquests resultats mostren que la imatge del flux immigratori procedent de l'estranger que s'associa a un nivell baix de formació es correspon, en tot cas, a etapes immigratòries del passat.

En el context metropolità, Barcelona és lloc de destinació preferent de la població més formada. En absència d'aquests mateixos registres per a la resta de municipis, les dades del cens de 2011 així ho manifesten: el 56\% de la població de 25 a 39 anys que va arribar al municipi de Barcelona entre 2007 i 2011 tenia estudis universitaris, comparat amb el $32 \%$ de persones amb el mateix nivell d'instrucció que van arribar a la resta de municipis de la metròpoli.

\section{LA SELECCIÓ VA PER BARRIS}

No tots els barris de la ciutat atreuen al mateix tipus de població. Existeix una notable heterogeneïtat per barris segons el perfil educatiu dels migrants que arriben a la ciutat, tal i com es pot veure als mapes inclosos a la Figura 2A. Si atenem a la distribució absoluta dels fluxos immigratoris, els barris més cèntrics de la ciutat són la destinació preferent de la població amb un nivell d'instrucció més elevat. La població de nacionalitat espanyola es concentra de forma notable al barri de la Vila de Gràcia, tot i que també es localitza preferentment a tots els barris de l'Eixample, així com a les extensions d'aquesta àrea central cap a Sants-Montjuïc (Sants i Poble Sec), Les Corts, Sarrià-Sant Gervasi i Sant Martí (als barris més meridionals). A més d'aquests barris, la població amb estudis universitaris de nacionalitat estrangera es concentra de forma destacada als barris del districte de Ciutat Vella.

Els barris més allunyats del centre de la ciutat sobresurten com a àrees amb poca presència de la població més formada que acaba d'arribar. Els barris del districte de Nou Barris i d'Horta-Guinardó, els més propers a la ribera del Besòs i que pertanyen a Sant Andreu i Sant Martí, i els barris de la
Marina de Port i de la Marina del Prat Vermell a Sants-Montjuï, presenten fluxos d'entrada de població amb estudis universitaris molt baixos. En canvi, aquestes zones són les que apareixen com a llocs destacats d'arribada de la població menys instruïda, sobretot en el cas de la població de nacionalitat espanyola. Entre la població de nacionalitat estrangera, a més dels barris del Besòs i el Maresme, Trinitat Vella, Ciutat Meridiana, Roquetes i el Carmel, destaca de forma notable l'assentament al barri del Raval a Ciutat Vella i la seva extensió meridional cap al Poble Sec.

El contrast territorial entre barris és encara més evident quan s'analitza la proporció de persones amb estudis universitaris entre tota la població que ha arribat procedent de fora de la ciutat (Figura 2B). En un extrem de la distribució, a la Vila Olímpica del Poblenou el 74\% de la població de la franja d'edat 25-49 que ha arribat

FIGURA 2. Localització del flux immigratori en funció del seu perfil educatiu, 2011-14

A) Localització dels fluxos (Pobl. 25-49 anys. mitjana anual, 2011-14) Població de nac. espanyola

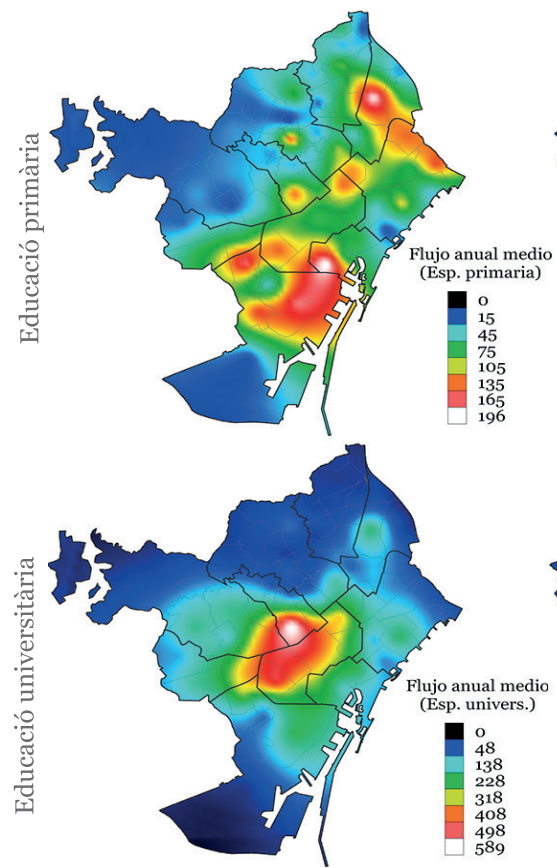

Població de nac. estrangera
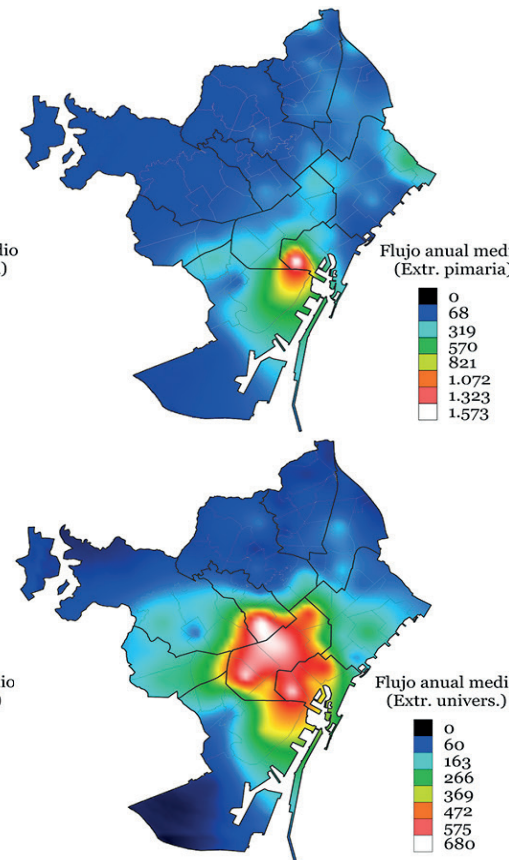

B) Proporció d'immigrants amb estudis universitaris (Pobl. 25-49 anys, \%)

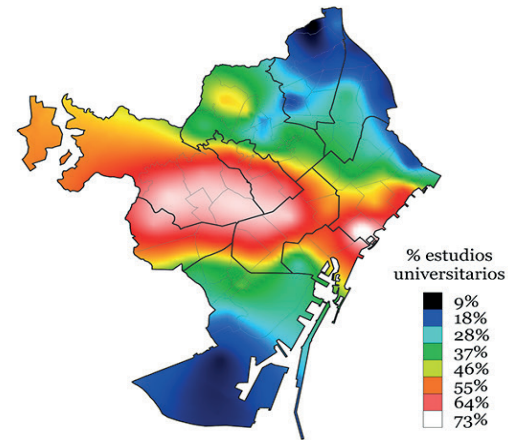

Font: Elaboració pròpia a partir del registre d'altes de l'Ajuntament de Barcelona 
al barri procedent de fora de la ciutat entre 2011 i 2014 té estudis universitaris. Els barris de Pedralbes, Sant Gervasi-Galvany, Sarrià i les Tres Torres s'apropen al 70\%. Els barris amb les proporcions més elevades tracen el recorregut de l'Avinguda Diagonal, sobretot per sobre d'aquesta al seu tram occidental (districtes de Les Corts i Sarrià-Sant Gervasi) i per sota al tram oriental (barris marítims de Sant Martí). A l'altre extrem de la distribució, barris com Ciutat Meridiana, Torre Baró o Trinitat Vella, assoleixen valors al voltant del 10\% de persones amb estudis universitaris entre la població que acaba d'arribar. Aquesta situació s'explica sobretot per la composició de la població de nacionalitat estrangera, principal protagonista del flux immigratori d'aquests barris.

\section{D'ON VINC O CAP A ON VAIG?}

Per completar la trama migratòria i residencial barcelonina precisem incorporar els canvis de domicili que es realitzen a l'interior del municipi. Només recentment comencem a tenir informació sobre aquest tipus de moviment ja que les fonts estadístiques tradicionals li han prestat poca atenció. Els moviments intraurbans són els més freqüents en el cas de Barcelona i es van totalitzar una mitjana anual de més de 100.000 entre 2011 i 2014. Per a cadascun d'aquests moviments coneixem el barri d'origen i de destinació.

Incideix el barri d'origen i el nivell d'instrucció dels individus en el barri de destinació del canvi de domicili? La resposta és afirmativa. La població que inicia el canvi de domicili als barris amb un nivell de Renda Familiar Disponible (RFD) més baix ${ }^{1}$ té una major probabilitat de romandre a barris del mateix nivell de renda (Figura 3). A mida que augmenta el nivell de renda del barri d'origen, la probabilitat de traslladar-se als barris del quintil més baix disminueix de forma clara. Als barris amb més renda s'observa la situació inversa: els individus que procedeixen dels barris més allunyats socioeconòmicament són els que menor probabilitat presenten de moure's cap a aquest àmbit, una probabilitat que augmenta a mesura que el barri d'origen presenta un perfil més elevat.

Els resultats més inèdits són els que s'obtenen en el moment en què incorporem a l'anàlisi el nivell d'instrucció de la població. El gradient educatiu resultant és molt marcat. La població amb estudis primaris que enceta el seu canvi de domicili als barris amb rendes

1. L'Ajuntament de Barcelona publica anualment la RFD per als 73 barris de la ciutat. Hem creat 5 grups de barris en funció del seu valor (Quintils), assegurant-nos que a cada grup resideix el 20\% de la població de Barcelona. Com a exemple, el Quintil Baix, inclou el 20\% de la població que resideix als barris amb una RFD més baixa. més baixes presenta un 70\% de probabilitats de situar la nova residència en el mateix grup de barris amb les rendes més baixes, comparat amb el 40\% de la població més formada. Dit d'una altra manera, la població amb estudis universitaris dels barris amb rendes més baixes té el doble de probabilitats de situar la nova residència en un barri de major renda que la població amb estudis primaris (el $60 \%$ contra el 30\%). El gradient educatiu es reprodueix en tots els grups de barri d'origen: conforme augmenta el nivell d'estudis, menor és la probabilitat de canviar de domicili als barris amb menor renda. En canvi, les probabilitats d'arribar a un barri de rendes altes s'incrementen a mesura que augmenta el nivell d'instrucció. El fet que cap de les línies es creui en funció del tipus de barri de partida mostra que en la destinació del teu canvi de domicili no només importa com ets, sinó també d'on vens.

FIGURA 3. Destinació dels canvis de domicili segons tipus de barri d'origen i nivell d’instrucció de la població (25-49 anys), 2011-2014
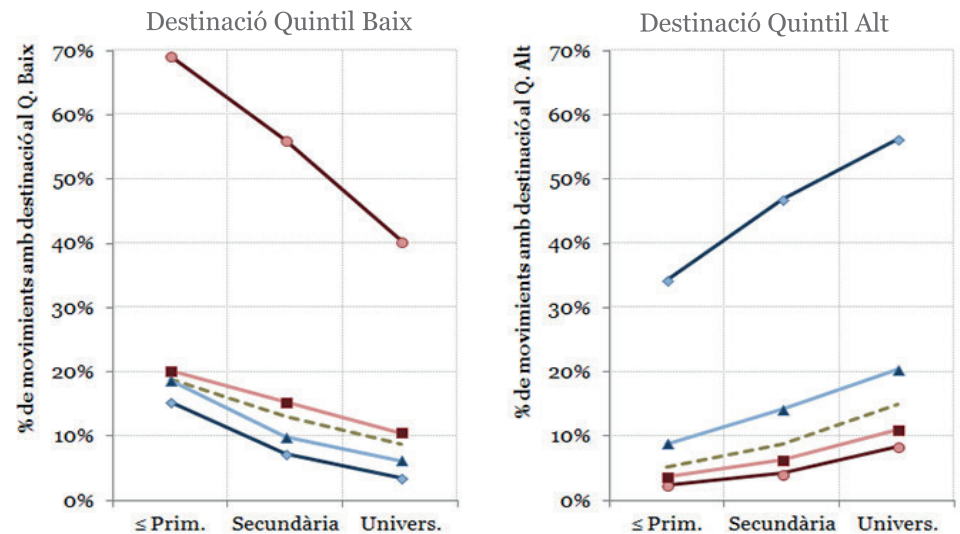

$$
\begin{array}{ll}
\text { Barri d'origen (Quintils segons Renda Familiar Disponible) } \\
\multimap \text { Q Baix } \quad \rightarrow-\text { Q Baix-Mig } \quad-- \text { - Q Mig } \quad-\text { Q Mig-Alt } \quad-\infty \text { QAlt }
\end{array}
$$

Nota: Es mostra la proporció de canvis de domicili que finalitzen el seu recorregut al grup de barris amb renda més baixa i més alta segons el tipus de barri d'origen i el nivell d'instrucció de lindividu. Només s'han inclòs les destinacions als barris dels quintils de renda més baixa i més alta.

Font: Elaboració pròpia a partir del registre de canvis de domicili de l'Ajuntament de Barcelona.

\section{CAP A LA POLARITZACIÓ DE BARCELONA? PLOU SOBRE MULLAT}

La inclusió de la migració i de la mobilitat residencial juntament amb el nivell d'instrucció en l'anàlisi de la desigualtat territorial permet caracteritzar la naturalesa dinàmica dels processos de segregació espacial i aportar nova evidència al debat sobre segregació i polarització territorial a Barcelona (Sarassa et al., 2013; Domingo i Blanes, 2015; Nel·lo, 2015). En aquest treball hem mostrat el rol dels canvis de residència de la població com a mecanisme amb una forta capacitat de perpetuar i accentuar les diferències en el territori. 
Barcelona és destinació preferent de població altament qualificada. Aquests fluxos, a més, tendeixen a concentrar-se a determinades zones de la ciutat, per regla general les més cèntriques, uns sectors als que gairebé no arriba població de baix nivell educatiu, que a la seva vegada s'assenta, amb poques excepcions, als barris més allunyats del centre municipal. Per altra banda, el patró actual de la mobilitat residencial interna dels barcelonins accentua les ja existents diferències socioeconòmiques en el territori, plou sobre mullat. Els barris amb les rendes familiars més baixes retenen i atrauen, amb diferència, a la població dels estrats socioeconòmics més baixos, que no ascendeixen a l'escala residencial, i els barris amb major renda retenen $\mathrm{i}$ atrauen als estrats socials millor situats. No hi ha dubte, doncs, que ambdues dinàmiques estan alimentant el procés de polarització socioeconòmica de la ciutat de Barcelona, en la línia del què succeeix a altres ciutats europees (Tammaru et al., 2016). Ara bé, l'absència de dades anteriors a l'any 2011 no ens permet afirmar si aquest procés s'està experimentant amb més intensitat que en el passat. A més, no disposem d'aquestes dades per a la resta dels municipis de la conurbació barcelonina. La nostra hipòtesi és que els mecanismes de selecció dels fluxos residencials i migratoris serien encara més forts si es contemplessin a escala metropolitana.

L'atracció de població molt formada té els seus efectes al mercat de l'habitatge, que ha traduït aquesta pressió en un recent augment dels preus als sectors en què es concentra la demanda. No és una situació nova si la contemplem en una perspectiva històrica, però sí que representa una novetat des de l'inici de la crisi econòmica. Si l'actual tendència es perllonga en el temps, i per tant, augmenta la pressió en aquests sectors centrals, és d'esperar que cada cop més persones es despengin d'aquesta cursa per residir als barris més el-lititzats i incloguin de forma progressiva altres zones en les seves trajectòries residencials. De l'experiència d'altres ciutats que s'han especialitzat en atreure població altament qualificada sabem que en determinats sectors de la ciutat l'habitatge s'ha convertit en un bé exclusiu (i excloent) i que aquesta àrea d'exclusivitat s'expandeix des dels barris centrals, generant una progressiva suburbanització de la pobresa (Hochstenbach, C. i Musterd, S., 2016). És cert que en el cas barceloní, degut a la menor freqüència amb què canviem d'habitatge no és d'esperar que aquests processos s'experimentin de forma tan ràpida com a altres ciutats del món. Malgrat tot, ara, més que mai, hem d'estar atents a la capacitat de la mobilitat residencial per alterar la composició socioeconòmica dels nostres barris.

L'èxit de la ciutat si el mesurem en la seva capacitat d'atreure talent i població qualificada té com a contrapartida la concentració de la població en àrees determinades o la seva expulsió cap a àrees suburbanes. A més, no podem oblidar que l'atracció de talent no hauria de descuidar mai, tampoc, la creació de talent (Capel, 2015). Per a que Barcelona no mori d'èxit, el model a seguir ha d'incorporar polítiques redistributives dels beneficis que genera l'atracció de població qualificada. L'articulació metropolitana d'aquestes polítiques és essencial.

\section{Referències bibliogràfiques}

Cabré, A.; Pujadas, I. (1982) Población y recursos humanos en Catalunya, a Reconeixement Territorial de Catalunya. Barcelona: Generalitat de Catalunya, Departament de Política Territorial i Obres Públiques, vol. 6 i 7

Capel, H. (2015) Pensar la ciudad en tiempos de crisis. Barcelona: Icaria.

Domingo, A.; Blanes, A. (2015) Demografia de la Barcelona Metropolitana: elements prospectius a l'horitzó 2030, Papers de Treball del Pla Estratègic Metropolità de Barcelona, http://www.pemb.cat/public/ docs/28_hc_2.pdf.

Hochstenbach, C.; Musterd, S (2016) Changing urban geographies through boom and bust periods: gentrification and the suburbanization of poverty,
Centre for Urban Studies WPS, núm. 17.

López-Gay, A. (2008) Canvis resi dencials $i$ moviments migratoris en la renovació poblacional de Barcelona. Barcelona, CTESC.

Nel-lo, O. (2015) La ciudad en mov imiento. Crisis social y respuesta ciudadana. Madrid, Díaz \& Pons.

Sarasa, S.; Porcel, S.; Navarro-Varas, L. (2013) L'impacte social de la crisi a l'Àrea Metropolitana de Barcelona i a Catalunya, Papers, núm. 56.

Tammaru T.; Marcińczak, S.; Van Ham, M.; Musterd, S. (2016) Socioeconomic segregation in European capital cities: East meets west. New York-London: Routledge.

\section{Agraiiments}

Departament d'Estadística, Ajuntament de Barcelona.

\section{Editors}

Andreu Domingo i Albert Esteve

Correspondència dirigida a:

Antonio López-Gay

tlopez@ced.uab.cat

\section{Crèdits}

Revisió i comentaris: Juan Antonio

Módenes, Hermínia Pujol i Joan Sales.

Cita

López-Gay, A. (2016) “Atracció de talent $i$ polarització socioeconòmica a Barcelona", Perspectives Demogràfiques, núm. 3, pp. 1-4.

\section{Maquetació}

Ester Angulo
Enllaç url

http://ced.uab.es/difusio/butlletiperspectives-demografiques/

\section{Contacte}

Centre d'Estudis Demogràfics. Carrer de Ca n’Altayó, Edifici E2 Universitat Autònoma de Barcelona 08193 Bellaterra / Barcelona Espanya

Telèfon: +34 935813060 Mail: demog@ced.uab.es Web: http://ced.uab.es/ 